\title{
CONFINADAS EM SI MESMAS: A MORTE SOCIAL E O ISOLAMENTO DO SUJEITO EM O CONTO DA AIA, DE MARGARET ATWOOD
}

\author{
Confined in themselves: social death and the isolation of the subject in \\ Margaret Atwood's The Handmaid's Tale
}

\author{
Jade Bueno Arbo \\ https://orcid.org/0000-0001-5726-6545 \\ Universidade Federal de Pelotas, Programa de Pós-Graduação em Filosofia, Pelotas, RS, \\ Brasil.96001-970 - ppgfilosofia@ufpel.edu.br

\section{Eduardo Marks de Marques} \\ (iD) http://orcid.org/0000-0002-3067-7237 \\ Universidade Federal de Pelotas, Centro de Letras e Comunicação, Pelotas, RS, Brasil. \\ 96010-610-ascomclc@gmail.com
}

\begin{abstract}
Resumo: Em $O$ Conto da Aia, de Margaret Atwood, a República de Gilead submete suas mulheres ainda férteis a uma série de atos que resultam em uma condição particular de morte em vida, uma condição a qual podemos chamar de morte social. Essa aparece em sua forma mais extrema, segundo Patterson (1985), na instituição da escravidão. A partir do estudo de Patterson, Lisa Guenther (2013) investiga os mecanismos que fazem e desfazem uma pessoa tanto externa (socialmente) quanto internamente (subjetivamente). O presente trabalho propõe que a interpretação da condição das Aias em Gilead como uma condição de escravidão abre portas para a compreensão das práticas sociais que geram o efeito da morte social desses sujeitos, bem como para a compreensão das condições de possibilidade do regime representado pela obra em questão, que de início pode nos parecer tão extremo, mas que tem como sua base mecanismos familiares de exclusão e violação.
\end{abstract}

Palavras-chave: Distopia. Morte social. O Conto da Aia.

Abstract: In The Handmaid's Tale, by Margaret Atwood, the Republic of Gilead submits the women who are still fertile to a series of acts that result in a particular condition of death in life, a condition which can be called social death, which appears in its more extreme form, according to Patterson (1985), in the institution of slavery. From Patterson's study, Lisa Gunther (2013) investigates the apparatus involved in making and unmaking someone's personhood both externally (socially) and internally (subjectively). This paper proposes that the interpretation of the Handmaid's condition as a condition of slavery allows for the understanding of the social practices that generate the effect of these subjects' social death, as well as the understanding of

Esta obra está licenciada sob uma Creative Commons - Atribuição 4.0 
the conditions of possibility of the regime presented by Atwood's dystopia, which might seem extreme and far-fetched, but has its roots on a familiar apparatus of exclusion and violation.

Keywords: Dystopia. Social death. The Handmaid's Tale.

\section{Introdução}

O Conto da Aia, de Margaret Atwood (2017), nos introduz à República de Gilead, um Estado teocrático e totalitário fundado e controlado por fundamentalistas cristãos. Como solução para a queda da natalidade que acomete Gilead, consequência da exposição à radiação, as poucas mulheres ainda férteis são separadas de suas famílias e privadas de seus direitos como cidadãs para formarem uma classe particular de indivíduos nessa sociedade: as "Aias". Elas existem em Gilead para fins de reprodução, para darem filhos aos Comandantes da Fé (líderes da República) e às Esposas. Para isso, são levadas de comandante a comandante, sendo submetidas aos "rituais de concepção", gerando a criança, alimentando-a enquanto necessário, e então partindo para a próxima casa.

Em Gilead, temos as aias reduzidas a um estado de não existência, confinadas a um não lugar na sociedade. Como resume Malak (2001), "são confinadas a um lugar semelhante a uma prisão para estarem disponíveis para relações sexuais periodicamente programadas com seus 'Comandantes da Fé'”' (2001, p. 3, tradução nossa)'.

As Aias não se juntam voluntariamente a essa classe de mulheres: elas são forçosamente destituídas de suas vidas e identidades prévias para se tornarem propriedade do Estado e distribuídas a seu critério. O seu bem-estar importa apenas na medida em que estejam fortes o suficiente para executarem sua função de geradora; sua subjetividade é anulada por uniformes, por interação intersubjetiva limitada e por uma total privação da liberdade.

As Aias, portanto, se encontram em um limbo da (ine)existência social, impossibilitadas tanto de participar daquela sociedade quanto de formar qualquer sociedade. Instrumentalizadas em função de sua capacidade reprodutiva em prol de um bem maior, as Aias têm seu próprio status de pessoa revogado. Mas como isso é possível? Como é possível que um indivíduo humano, tendo sido um dia reconhecido como pessoa, tenha esse caráter tirado de si? Basta uma lei, um decreto para que isso aconteça, ou é necessário mais do que isso?

Judith Butler (2018), em Quadros de guerra: quando a vida é passivel de luto, coloca que "uma vida específica não pode ser considerada lesada ou perdida se não for primeiro considerada viva" (2018, p. 13), e essa condição de ser reconhecido não é, segundo a filósofa, "uma qualidade ou potencialidade de indivíduos humanos" (2018, p. 19), pois assim todo o ser humano seria automaticamente considerado uma "vida" e o problema estaria resolvido, o que não é o caso. Butler (2018) aponta, assim, que é possível que se seja humano e, ao mesmo tempo, não seja reconhecido como uma pessoa, como "vidas passíveis de luto" (2018, p. 11). A partir disso, pensar o (não) lugar das Aias em Gilead é, ao mesmo tempo, pensar as condições de reconhecimento de seres humanos enquanto pessoas, é pensar como se sustenta (e se destrói)

\footnotetext{
1 "are confined to a prison-like compound in order to be available for periodically programmed sexual intercourse with their "Commanders of the Faith." (MALAK, 2001, p. 3).
} 
a própria condição de pessoa de um indivíduo.

Lisa Guenther (2013), em seu livro Solitary confinement: social death and its afterlives, se propõe a investigar os mecanismos que fazem e desfazem uma pessoa tanto externa (socialmente) quanto internamente (subjetivamente). Sobre o caráter de pessoa de um indivíduo, Guenther (2013) declara:

É necessária toda uma rede de obrigações interconectadas, tanto no presente quanto se estendendo no passado e no futuro, para criar e sustentar a condição de pessoa de um indivíduo (personhood), e é necessária toda uma rede de exclusões, interrupções e violações, não apenas contra os indivíduos mas contra os horizontes sociais e temporais de suas vidas, para destruir essa condição de pessoa. (2013, p. xx-xxi, tradução nossa) ${ }^{2}$.

Para realizar esse estudo, Guenther (2013) lança mão do estado mais extremo da despersonalização, a escravidão, utilizando-se do trabalho de Orlando Patterson (1985), Slavery and social death: a comparative study, para compreender a condição de existência dessa despersonalização: a morte social. É a partir do insight de Guenther (2013) que se constrói o presente trabalho: de que, para que seja possível pensar a condição de pessoa de um indivíduo como passível de destruição através de práticas sociais, essa condição de pessoa deve ser pensada necessariamente como construída e mantida, da mesma forma, por meio de práticas sociais.

O presente trabalho propõe, portanto, que interpretar a condição das Aias em Gilead como uma condição de escravidão abre portas para a compreensão das práticas sociais que geram o efeito da morte social desses sujeitos, bem como para a compreensão das condições de possibilidade do regime representado pela obra em questão, que de início pode nos parecer tão extremo, mas que tem como sua base mecanismos familiares de exclusão e violação. A partir da localização da morte social desses sujeitos, pretende-se, também, examinar as consequências desse isolamento para esses indivíduos, argumentando para uma concepção intersubjetiva da constituição dos mesmos, e contra uma visão atomística de selfhood.

Primeiramente, discutiremos na primeira seção a localização de $O$ Conto da Aia na tradição distópica, e se argumentará para o potencial filosófico das distopias, as quais, ao extrapolarem o presente, nos fornecem exemplos com os quais sociólogos e filósofos sequer sonhariam. Na segunda seção, argumenta-se para a interpretação da situação das aias como uma situação de escravidão, analisando as possibilidades de leitura que esse paralelo abre, e uma maior compreensão do conceito de morte social através do exemplo das Aias. Por fim, na última seção, explora-se as consequências internas da morte social para as Aias a partir da perspectiva de Guenther (2013) acerca do confinamento solitário.

\footnotetext{
2 "It takes a whole network of interconnected obligations, both in the present and extending into the past and future, to create and sustain social personhood, and it takes a whole network of exclusions, interruptions, and violations, not only against individuals but against the social and temporal horizons of their lives, to destroy that personhood" (GUENTHER, 2013, p. xx-xxi).
} 


\section{O Conto da Aia como distopia e seu potencial filosófico}

No decorrer da narrativa de $O$ Conto da Aia, nosso único acesso ao universo descrito anteriormente é através do mundo interno de Offred, uma Aia que transita entre passado e presente, contando sua história e nos permitindo traçar os paralelos necessários para o caráter especulativo da ficção de Margaret Atwood, onde extrapolar os discursos presentes para suas consequências mais radicais serve como forma de aviso.

Essa é uma das características que situam $O$ Conto da Aia em uma tradição literária distópica. Segundo Amin Malak (2001), embora distopias façam uso do medo e do horror em suas narrativas, "a ênfase do trabalho não é no horror por si mesmo, mas no alerta" (2001, p. 4, tradução nossa) ${ }^{3}$; da mesma forma, o excesso e exagero nas imagens trazidas pelas distopias não seria advindo de um ímpeto fantástico escapista, mas sim "permitir que certas tendências na sociedade moderna se desenvolvam sem o freio do sentimento e da humanidade" (MALAK, 2001, p. 5, tradução nossa $)^{4}$.

Malak (2001) também enfatiza a forma como distopias "dramatizam o eterno conflito entre escolha individual e necessidade social” (2001, p. 5, tradução nossa) ${ }^{5}$, tema central na República de Gilead, onde indivíduos são destituídos de sua individualidade - e, como será argumentado no decorrer do trabalho, de sua condição de pessoa (personhood) - por um "bem maior": a manutenção da taxa de natalidade, e, por conseguinte, daquela sociedade como um todo.

Além disso, talvez no apontamento trazido por Malak (2001) que mais nos seja útil aqui, os romances distópicos possuem um caráter de roman à thèse:

Em diferentes níveis, distopias são quintessencialmente romances ideológicos: eles envolvem o leitor no que Fredrick Jameson chama de um "discurso teórico", através do qual diversas possibilidades temáticas são postuladas e polarizadas umas contra as outras, mas os romances eventualmente revelam uma visão filosófica e sociopolítica definitiva para a qual a ficção se prova um meio conveniente. (2001, p. 6, tradução nossa) ${ }^{6}$.

Portanto, pensar O Conto da Aia sob esta perspectiva é utilizar-se de sua potencialidade filosófica no que tange os diversos temas que o romance traz, buscando desvendá-los como experimentos de pensamento filosóficos.

Jonathan Culler (2000), em seu capítulo "The Literary in Theory" para o livro What's left of theory: new work on the politics of literary theory, chama a atenção para o fato de que se mitos são boas ferramentas para se pensar, a literatura é uma ferramenta ainda melhor,

\footnotetext{
3 "the emphasis of the work is not on horror for its own sake, but on forewarning" (MALAK, 2001, p. 4).

4 "to allow certain tendencies in modern society to spin forward without the brake of sentiment and humaneness" (MALAK, 2001, p. 5).

5 "dramatize the eternal conflict between individual choice and social necessity" (MALAK, 2001, p. 5).

6 "To varying degrees, dystopias are quintessentially ideological novels: they engage the reader in what Fredrick Jameson calls a "theoretical discourse," whereby a range of thematic possibilities are posited and polarized against each other, yet the novels eventually reveal a definite philosophical and socio-political outlook for which fiction proves to be a convenient medium.” (MALAK, 2001, p. 6).
} 
apontando a dinâmica de singularidade e exemplaridade na literatura como indicativo disso, principalmente para a questão da identidade, tão cara à produção filosófica recente:

Romances, poemas e peças de teatro, em sua singularidade, se negam a explorar aquilo do que eles são exemplos ao mesmo tempo em que convidam seus leitores a se tornar envolvidos nos predicamentos e nas consciências de narradores e personagens que são em algum sentido postulados como exemplos de algo (exemplary). Essa estrutura de exemplaridade tem sido importante para a relação entre literatura e o problema da identidade, o qual tem sido tão central para a teoria recente. Seria o self algo dado ou algo feito e deveria ele ser concebido em termos individuais ou sociais? (CULLER, 2000 , p. 282, tradução nossa) ${ }^{7}$.

A literatura, segundo Culler (2000), é plena de tais temas, com os quais sempre se preocupou, oferecendo "uma variedade de modelos implícitos de como a identidade é formada" (CULLER, 2000, p. 282, tradução nossa) $)^{8}$ : algumas narrativas oferecem uma versão de que a identidade é dada ao nascimento, outras por identificação, e outras se mostram em períodos atribulados da vida dos personagens (CULLER, 2000).

Culler (2000) afirma que:

A explosão de teorização sobre raça, gênero e sexualidade no campo dos estudos literários talvez deva muito ao fato de que literatura fornece materiais ricos para relatos políticos e sociológicos complicadores do papel de tais fatores na construção da identidade. (2000, p. 283, tradução nossa) ${ }^{9}$.

Embora o presente trabalho não se atenha majoritariamente a questões de identidade (ainda que identidade e reconhecimento estejam intrinsecamente conectadas), o insight de Culler é valioso, pois indica que a crítica literária pode se tornar, também, um exercício filosófico de exame desses elementos constitutivos, e o texto literário não apenas se torna o objeto de análise em si, mas também ferramenta de análise do humano (e das concepções de humano), por meio de exemplos, nas palavras de Culler (2000), “jamais sonhadas por sociólogos" (2000, p. 283, tradução nossa) $)^{10}$.

É sobre essa premissa que os argumentos a seguir se constituem.

\section{Morte em vida: as Aias e sua morte civil e social}

Nós dormimos no que antes havia sido o ginásio esportivo. [...] tentávamos dormir, nos catres do exército que haviam sido dispostos em fileiras, espaçados de modo que não pudéssemos conversar. [...] Tia Sara e Tia

\footnotetext{
7 "Novels, poems, and plays, in their singularity, decline to explore what they are exemplary of at the same time that they invite their readers to become involved in the predicaments and the consciousness of narrators and characters who are in some sense posited as exemplary. This structure of exemplarity has been important to the relationship of literature to the problem of identity, which as been so central to recent theory. Is the self something given or something made and should it be conceived in individual or in social terms" (CULLER, 2000, p. 282).

8 "a range of implicit models of how identity is formed" (CULLER, 2000, p. 282).

9 "The explosion of recent theorizing about race, gender, and sexuality in the field of literary studies may owe a good deal to the fact that literature provides rich materials for complicating political and sociological accounts of the role of such factors in the construction of identity." (CULLER, 2000, p. 283).

10 "undreamt of by sociologists" (CULLER, 2000, p. 283).
} 
Elizabeth patrulhavam; tinham aguilhões elétricos de tocar gado suspensos por tiras de seus cintos de couro. [...] As armas eram para os guardas. [...] não tínhamos permissão para sair, exceto para as caminhadas, duas vezes por dia, duas a duas, ao redor do campo de futebol que agora estava cercada por uma cerca reforçada de malha metálica com rolos de arame farpado no alto. (ATWOOD, 2017, p. 11-12).

O trecho que introduz o romance é uma descrição detalhada do Centro Vermelho, onde as Aias são mantidas. Sua situação é claramente de cárcere: vigiadas constantemente pelas Tias, dentro, e pelos Anjos, do lado de fora; os catres distantes o suficiente para evitar qualquer interação não mediada entre elas; o ambiente externo cercado. Ser uma Aia em Gilead não é uma opção.

Qual é, então, o lugar da Aia? Seria o seu posicionamento nessa sociedade o de uma prisioneira? Embora o discurso religioso das Tias denote que há muito pelo que as Aias, enquanto mulheres que um dia foram livres, devam se retratar, seu encarceramento não acontece como resposta a esses "crimes" (podendo ser mais adequado chamá-los de "pecados"), mas tendo em vista a função dessas mulheres. As Aias se tornam propriedade do estado e instrumentalizadas para a execução de uma tarefa, da qual não podem escapar, em prol da manutenção da sociedade.

Porém, embora vital para sua manutenção, a Aia não tem um lugar na sociedade, vivendo às margens, em um limbo, um "não lugar". Como a personagem coloca: "Somos para fins de procriação. [...] Somos úteros de duas pernas, apenas isso: receptáculos sagrados, cálices ambulantes" (ATWOOD, 2017, p. 165). O lugar da Aias é, portanto, o lugar da instrumentalização final dos corpos: um lugar de escravidão.

Guenther (2013) nos apresenta dois tipos de "morte" que um indivíduo pode sofrer, embora permaneça vivo: a morte civil e a morte social, sendo a primeira uma ficção legal e a segunda um efeito de uma prática social. A morte civil despe o indivíduo de seu status legal de pessoa, privando-o de "direitos civis tais quais o direito de possuir e transmitir propriedade, votar, levar um caso à justiça, etc." (GUENTHER, 2013, p. xviii, tradução nossa) ${ }^{11}$. A morte social, no entanto, é muito mais complexa: "embora tais pessoas estejam fisicamente vivas, suas vidas não mais carregam significância social; elas não mais contam como vidas que importam" (GUENTHER, 2013, p. xx, tradução nossa) ${ }^{12}$.

As Aias, assim como historicamente os escravos, passam por ambas as mortes, onde a primeira facilita a segunda: com o congelamento das contas de todas as mulheres dos Estados Unidos e sua subsequente retirada de direitos civis no universo de $O$ Conto da Aia, o próximo passo se torna as práticas de despersonalização desses indivíduos resumidas por Guenther (2013):

Os mortos civis e sociais são excluídos da participação completa na vida,

\footnotetext{
11 "civil rights such as the rights to own or bequeath property, to vote, to bring a legal case to court, and so on" (GUENTHER, 2013, p. xviii).

12 "physically alive, their lives no longer bear a social meaning; they no longer count as lives that matter" (GUENTHER, 2013, p. xx).
} 
como fantasmas que podem falar e agir, mas cujas falas e ações não causam mais impacto no mundo. Não podem nem intervir em nome de outros ou receber ajuda de outros que venham acudi-los. Todas as suas relações sociais passam pela mediação de um poder oficial investido com o direito de conceder e negar sua legitimidade civil e social. (GUENTHER, 2013, p. xxvii, tradução nossa $)^{13}$.

O conjunto de práticas de exclusão que geram a morte social age principalmente sobre a privação desses indivíduos de uma série de relações constitutivas da condição de pessoa: suas relações com o passado, com o futuro e com o presente (GUENTHER, 2013), sendo todas as suas relações - e sua própria existência - mediadas e dependentes da identidade de seu senhor.

No caso das Aias, seus nomes (ou ausência dos mesmos) simbolizam essa mediação. Eles são apagados e substituídos pelos nomes de seus senhores: Offred, Ofglen, Ofwayne, Ofwarren; e seus nomes mudam conforme o Comandante sob a tutela do qual se encontram no momento. Patterson (1985) traz o dito dos tuaregues do Saara para exemplificar essa dependência e mediação: "sem o senhor, o escravo não existe, e ele é socializável apenas através de seu senhor" (PATTERSON, 1985, p. 4, tradução nossa) ${ }^{14}$. O "senhor" da Aia é composto por uma dupla entre Estado e o Comandante que possui a Aia em determinado momento. Sem eles, para os quais a Aia cumpre sua função, a Aia não existe, pois nenhuma outra relação, como veremos a seguir, é reconhecida além da relação da Aia com sua função.

Sua relação com o presente é vedada na medida em que suas relações interpessoais são sempre intermediadas e não são reconhecidas oficialmente. As Aias não podem intervir umas pelas outras, os laços que formam são clandestinos e frágeis, podendo ser interrompidos a qualquer momento e sem qualquer explicação. Diante do desaparecimento inesperado e inexplicado de Ofglen, Offred nada pode fazer. Não há autoridades às quais possa recorrer e reivindicar em nome da mesma, perguntar sobre seu paradeiro. Sobre esse tipo de relação, Guenther (2013) esclarece:

Claro que escravos conseguiam formar laços fortes uns com os outros [...]. Mas essas relações eram formadas e sustentadas precisamente em resistência, e até em oposição, às estruturas que buscavam, deliberada e sistematicamente, barrá-las. (2013, p. xxi, tradução nossa) ${ }^{15}$.

Há, portanto, uma ansiedade sempre presente, uma insegurança em todas as relações firmadas pelas Aias entre elas, e entre elas e outras castas.

Da mesma forma, as Aias perdem sua relação com o passado pois perdem seu direito a

\footnotetext{
13 "The civil and social dead are excluded from full participation in life, like ghosts who can still speak and act but whose speech and actions no longer make an impact on the world. They can neither intervene on behalf of another nor receive the help of others who come to their aid. All of their social relations run through the mediation of an official power invested with the right to grant or withhold their civil and social legitimacy" (GUENTHER, 2013, p. xvii).

14 "without the master the slave does not exist, and he is socializable only through his master" (PATTERSON, 1985 , p. 4).

15 "Of course, slaves did manage to form strong ties with one another [...]. But these relationships were formed and sustained precisely in resistance, and even in opposition, to the structures that deliberately and systematically sought to foreclose them." (GUENTHER, 2013, p. xxi)
} 
uma história, a conexão com antepassados. Sendo forçadas a uma comunidade artificial e efêmera, separadas de suas famílias, as Aias não mais podem, como aponta Patterson (1985) sobre a condição dos escravos, "integrar livremente a experiência de seus ancestrais em suas vidas, [...] ancorar o presente vivido em qualquer comunidade de memória" (1985, p. 5, tradução nossa) ${ }^{16}$.

A relação com o futuro, por sua vez, é vedada pelo que Patterson (1985) chama de "alienação natal", segundo ele:

Foi essa alienação do escravo de quaisquer laços de sangue formais e legalmente garantidos e de qualquer conexão com grupos ou localidades que não fossem as que o senhor escolheu para ele que deu à relação de escravidão seu valor peculiar ao senhor. $\mathrm{O}$ escravo era o instrumento humano definitivo, marcável e descartável como o mestre o desejasse. (1985, p. 7, tradução nossa $)^{17}$.

Os filhos gerados pelas Aias anteriormente ao regime lhes foram tomados uma vez que seus corpos foram reivindicados para serem instrumentalizados pelo Estado, e os filhos gerados no novo regime não pertencem a elas. Quaisquer laços de sangue que pudessem ter foram desautorizados, de forma que pais e mães de Aias estariam impossibilitados e desautorizados de intervir por suas filhas. Dessa forma, as Aias sofrem um tipo de confinamento ao qual apenas a morte social é capaz de submeter um indivíduo, ilustrado pelas palavras de Guenther (2013):

A morte social é menos uma questão de ter os direitos e liberdades naturais de um indivíduo negados, do que é uma questão de ser isolado em sua individualidade, confinado a sua existência separada e vedado de qualquer sentimento significativo de pertencimento a uma comunidade que é maior do que a própria pessoa. Sem uma relação viva com gerações passadas e futuras, quem sou eu? Eu ainda tenho impacto no tempo histórico? Se o significado da minha vida é confinado a minha existência biológica, então se equivale a quase nada; um golpe rápido na cabeça, e pode estar tudo acabado. (2013, p. xxiii, tradução nossa) ${ }^{18}$.

Tal descrição revela não apenas as condições de existência de um regime como o de Gilead, mas também suas consequências para os sujeitos submetidos aos mesmos: a morte social despe o sujeito de qualquer possibilidade de vínculo estável, dessa forma, despindo-os também de qualquer referência para si no mundo.

\footnotetext{
16 "freely to integrate the experience of their ancestors into their lives, [...] to anchor the living present in any conscious community of memory." (PATTERSON, 1985, p. 5).

17 "It was this alienation of the slave from all formal, legally enforceable ties of "blood," and from any attachment to groups or localities other than those chosen for him by the master, that gave the relation of slavery its peculiar value to the master. The slave was the ultimate human tool, as imprintable and as disposable as the master wished." (PATTERSON, 1985, p. 5).

18 "In this sense, social death is less a matter of being denied the natural rights and freedoms of an individual than of being isolated in one's individuality, confined to one's separate existence and blocked from a meaningful sense of belonging to a community that is greater than oneself. Without a living relation to past and future generations, who am I? Do I still have a stake in historical time? If the meaning of my life is confined to my biological existence, then it amounts to almost nothing; one swift blow to the head, and it could all be over." (GUENTHER, 2013, p. xxiii).
} 
O confinamento ao qual as Aias são submetidas é duplo. Sua liberdade é privada por muros e janelas que não se abrem completamente, mas são, também, confinadas ao próprio corpo por vidros ausentes ou inquebráveis e outras medidas para a prevenção de suicídio.

Compreender as Aias enquanto indivíduos em situação de escravidão é essencial para que se compreenda do que se trata a morte em vida à qual são condenadas: ela é resultado de uma série de práticas civis e sociais de exclusão e deslegitimação que trabalham para despir um indivíduo de sua condição de pessoa. Como coloca Guenther (2013): “o morto socialmente não é meramente uma 'não pessoa', mas sim [...] uma 'pessoa despersonalizada'. São pessoas cuja significância social foi eliminada, como se não estivessem mais entre nós” (2013, p. xxiii, tradução nossa) ${ }^{19}$.

A presença das Aias é sim sentida na casa dos Comandantes. Elas são motivos de conflitos e focos desestabilizadores daqueles lares, mas essa presença sentida é como a de um espírito, e não como a de um indivíduo, pois não são reconhecidas como, para usar os termos de Butler (2018), uma vida passível de luto.

\section{Confinadas em si mesmas: o isolamento das Aias e a deterioração do sujeito}

O trabalho filosófico realizado por Guenther (2013) se utiliza da análise de depoimentos de pessoas submetidas ao encarceramento solitário em prisões dos Estados Unidos para responder à seguinte pergunta: "Como posso perder a mim mesmo sendo confinado a mim mesmo?" (2013, p. xii, tradução nossa) ${ }^{20}$, pois esses sujeitos, conforme a autora observa, ao serem submetidos ao completo isolamento (mortos civil e socialmente que são), tornam-se unhinged ${ }^{21}$.

Sua hipótese é a de que "para que isso seja possível, deve haver algo a mais à selfhood do que individualidade" (GUENTHER, 2013, p. xii, tradução nossa) ${ }^{22}$, propondo que não podemos ser concebidos simplesmente como indivíduos atomísticos, sendo que "a ausência do contato corporal regular com outros, a ausência de sequer a possibilidade de tocar e ser tocado" (GUENTHER, 2013, p. xiii, tradução nossa) ${ }^{23}$ ameaça tornar o sujeito transtornado, perturbado (unhinged).

Pensar o sujeito nesses termos é lançar nova luz aos processos internos de Offred, seu sofrimento, a deterioração de seu estado mental, e a ânsia pelo Outro que percebemos nela em trechos como o a seguir:

\footnotetext{
19 'the social dead are not merely nonpersons but rather [...] 'depersonalized persons.' They are persons whose social significance has been crossed out, as if they were no longer with us." (GUENTHER, 2013, p. xxiii).

20 "How could I lose myself by being confined to myself?" (GUENTHER, 2013, p. xii).

${ }^{21} \mathrm{O}$ termo em inglês unhinged pode ser traduzido como "desequilibrado", mas em inglês a palavra "hinge" remete a articulações, a objetos que conectam uma coisa à outra de forma a fazê-las mover-se adequadamente. $\mathrm{O}$ termo, para a autora, é essencial para a sua argumentação, sendo o termo unhinged "uma descrição fenomenológica precisa do que acontece quando as juntas articuladas da nossa subjetividade corporificada e interrelacional são desmembradas (GUENTHER, 2013, p. xii, tradução nossa ["It is a precise phenomenological description of what happens when the articulated joints of our embodied, interrelational subjectivity are broken apart."])

22 "For this to be possible, there must be more to selfhood than individuality." (GUENTHER, 2013, p. xii).

23 "the absence of regular bodily contact with others, the absence of even the possibility of touching or being touched" (GUENTHER, 2013, p. xiii).
} 
Como eu costumava desprezar esse tipo de conversa. Agora anseio por elas. Pelo menos eram conversas. Uma troca, por menor que fosse. Ou conversaríamos sobre a vida dos outros. [...] Ou eu ajudaria Rita a fazer o pão, mergulhando as mãos naquele calor resistente e suave que se parece tanto com o de nossa carne. Anseio por tocar alguma coisa, algo que não seja pano ou madeira. Anseio por cometer o ato do toque. (ATWOOD, 2017, p. 20).

A proibição do "ato do toque" é uma das práticas da qual depende a morte social, e sua consequência é o isolamento completo desses sujeitos. Seguindo a proposta de Guenther (2013), esse desejo pelo toque e pela interação que vemos em Offred é fruto não apenas da necessidade do sujeito para a felicidade do sujeito, mas sim para a própria constituição do mesmo enquanto sujeito. Suas mãos tocam apenas pano ou madeira, mas não outros sujeitos, e essa é uma forma de "desmembrá-lo", de torná-lo desconexo com sua realidade, de corroer sua subjetividade.

Quando em total isolamento, Offred busca momentos de seu passado, e, neles, uma conexão com esses Outros. Contar histórias é uma tentativa desesperada de manter-se sã, de manter-se consciente de sua existência e de sua identidade, mas histórias precisam ser contadas a alguém, e, na ausência de qualquer possibilidade de interação, ela se dirige a um "você" imaginário.

Mas se for uma história, mesmo em minha cabeça, devo estar contando-a para alguém. Você não conta uma história para si mesma. Sempre existe outra pessoa.

Mesmo quando não há ninguém.

Uma história é como uma carta. Caro Você, direi. Apenas você, sem nome. [...] Fingirei que você pode me ouvir.

Mas não adianta, porque sei que não pode. (ATWOOD, 2017, p. 52).

Tal trecho marca a dependência de um "você" para a existência de um "eu". Se minha história só existe ao ser contada, ela não pode ser contada a não ser que alguém possa ouvi-la, portanto a minha existência dependeria da recepção de outros dessa minha existência. "Sempre existe outra pessoa", pois essa não existência acarreta na inexistência do sujeito mesmo.

Uma história contada a um "você" imaginário ou recursos ao passado de pessoas não mais presentes não são suficientes, no entanto, para evitar que o sujeito se deteriore em seu isolamento. Como explica Guenther (2013):

A percepção da condição concreta de pessoa depende essencialmente da relação corporificada com outras consciências corporificadas em um mundo partilhado. O mundo não é apenas o "ambiente" de um organismo que responde a estímulos; ao invés disso, é o horizonte final da experiência significativa. A percepção do mundo é co-constituída com outros, mesmo que sua condição final de possibilidade seja uma consciência em primeira pessoa. $\left(2013\right.$, p. xxviii, tradução nossa) ${ }^{24}$.

\footnotetext{
24 "the sense of concrete personhood relies essentially upon embodied relations to other embodied consciousnesses in a shared world. The world is not just the "environment" of an organism that responds to stimulation; rather, it is the ultimate horizon of meaningful experience. The sense of the world is coconstituted with others, even if its ultimate condition of possibility is first-person consciousness." (GUENTHER, 2013, p. xxviii).
} 
Vedada dessa co-constituição, Offred, assim como as outras escravas de Gilead, tem sua própria percepção da sua condição concreta de pessoa ameaçada. Sua ânsia pelo toque, por trocas e conexão com outros indivíduos, assim, é fruto de um ímpeto desesperado de mantê-la, pois "esse é o poder da vida social: não (apenas) a autonomia de um sujeito soberano, mas também o apoio mútuo de uma rede de relacionamentos protetivos concreta, mas aberta (GUENTHER, 2013, p. xxiii, tradução nossa) ${ }^{25}$.

Offred, Ofglen, Ofwayne, Ofwarren têm seus nomes substituídos para evitar o que Guenther (2013) chama de "contragenealogias" que possam deslegitimar o caráter de propriedade daquele sujeito escravizado. A garantia do escravo como propriedade (no caso das Aias, do Estado e de seus Comandantes) acaba por ameaçar mais do que apenas a relação desses sujeitos com outros concretos, mas também sua relação com "possíveis outros e com a fecundidade do tempo" (GUENTHER, 2013, p. xxii, tradução nossa) ${ }^{26}$. A troca do nome e a vedação de contragenealogias atua não apenas como ferramenta da morte social, mas também como ferramenta de uma aniquilação da subjetividade através da impossibilitação da mesma, considerando que a subjetividade é necessariamente co-constituída.

Nossa relação com outros corporificados e com possíveis outros futuros

mantêm aberta a promessa de uma rota de fuga da dominação e exclusão presentes, um sentimento de que as coisas poderiam ser de outra forma, que o futuro não está sempre determinado pela intervenção do senhor. (GUENTHER, 2013, p. xxii, tradução nossa) ${ }^{27}$.

O constante ataque a essa promessa é uma violação contra os horizontes sociais e temporais desses indivíduos, que destroem sua condição de pessoa não apenas externamente, através de um não reconhecimento de suas vidas como vidas, mas também internamente, através da deterioração da sua consciência da própria condição de pessoa (personhood).

No decorrer deste trabalho, a distopia vista enquanto terreno fértil para a investigação filosófica permitiu-nos levar as rupturas apresentadas por O Conto da Aia às suas consequências lógicas: se a condição de pessoa de um indivíduo pode ser desfeita, isso nos leva a crer que essa condição é menos um dado metafísico e mais um efeito de movimentos sociais constantes; se a consciência da própria condição de pessoa por parte de um indivíduo pode ser ameaçada, isso nos leva a crer que ela depende muito menos de uma percepção interna atomística e mais de uma realidade co-constituída com outros corporificados.

Assim, não seríamos tão passíveis de despersonalização se a nossa condição de pessoas não fosse tão dependente da rede de obrigações interconectadas, da qual fala Guenther (2013), que a sustenta. Da mesma forma, a morte social não seria uma condenação tão cruel se a vida social não fosse o próprio vetor dessa condição. Sem ela, ou seja, sem outros corporificados, as

\footnotetext{
25 "This is the power of social life: not (just) the autonomy of a sovereign subject, but the mutual support of a concrete but open-ended network of protective relationships." (GUENTHER, 2013, p. xxiii)

26 "possible others and to the fecundity of time." (GUENTHER, 2013, p. xxii)

27 "hold open the promise of an escape route from present domination and exclusion, a sense that things could be otherwise, that the future is not always already determined by the master's intervention." (GUENTHER, 2013, p. xxii).
} 
condições de possibilidade da nossa existência no mundo são vedadas, e nos tornamos, como as Aias, mortos em vida.

\section{Referências}

ATWOOD, Margaret. O conto da Aia. Rio de Janeiro: Rocco, 2017.

BUTLER, Judith. Quadros de guerra: quando a vida é passível de luto?. Rio de Janeiro: Civilização Brasileira, 2018.

CULLER, Jonathan. The literary in theory. In: BUTLER, Judith; GUILLORY, John; THOMAS, Kendall. (Eds.) What's left of theory: new work on the politics of literary theory. London: Routledge, 2000, p. 273-292.

GUENTHER, Lisa. Solitary confinement: social death and its afterlives. Minneapolis: University of Minnesota Press, 2013.

MALAK, Amin. Margaret Atwood's The Handmaid's Tale and the Dystopian Tradition. In: BLOOM, Harold. (Ed.) Margaret Atwood's The Handmaid's Tale. Langhorne, Pennsylvania: Chelsea House Publishers, 2001, p. 03-10.

PATTERSON, Orlando. Slavery and social death: a comparative study. Minneapolis: University of Minnesota Press, 1985.

\section{NOTAS DE AUTORIA}

Jade Bueno Arbo (jade.arbo@ufpel.edu.br) é mestranda no Programa de Pós-Graduação em Filosofia pela Universidade Federal de Pelotas (PPGFil-UFPel) e graduada pelo curso de bacharelado Letras com ênfase em Redação e Revisão de Textos pela mesma universidade (2017). Desenvolve trabalhos nas áreas de Gênero e Linguagem, Filosofia Feminista e intersecções entre Filosofia e Literatura.

Eduardo Marks de Marques (eduardo.marks@ufpel.edu.br) é graduado em Letras Português e Inglês (UFRGS, 1999); Mestre em Letras - Inglês e Literatura Correspondente (UFSC, 2002); PhD em Literatura e História Cultural Australiana (University of Queenland, 2007), com Estágio Pós-Doutoral em Estudos Literários (UFMG, 2014). Professor Associado II de literaturas de língua inglesa e teoria literária na Universidade Federal de Pelotas.

\section{Como citar esse artigo de acordo com as normas da revista}

ARBO, Jade Bueno; MARQUES, Eduardo Marks de. Confinadas em si mesmas: a morte social e o isolamento do sujeito em $O$ conto da Aia, de Margaret Atwood. Anuário de Literatura, Florianópolis, v. 24, n. 2, p. 164-176, 2019.

\section{Contribuição de autoria}

Jade Bueno Arbo: concepção, redação, análise de dados e discussão de resultados.

Eduardo Marks de Marques: análise de dados e discussão de resultados.

\section{Financiamento}

Não se aplica. 
Consentimento de uso de imagem

Não se aplica.

Aprovação de comitê de ética em pesquisa

Não se aplica.

\section{Licença de uso}

Este artigo está licenciado sob a Licença Creative Commons CC-BY. Com essa licença você pode compartilhar, adaptar, criar para qualquer fim, desde que atribua a autoria da obra.

\section{Histórico}

Recebido em: 31/07/2019

Aprovado em: 16/10/2019

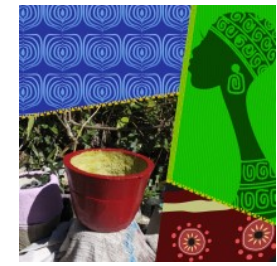

